\title{
Evaluation of Dental Anxiety in Parents Accompanying their Children for Dental Treatment
}

\author{
Dr Parajeeta Dikshit,' Dr Senchhema Limbu,2 Ms Kreepa Bhattarai3 \\ 1.2Lecturer, Department of Pediatric Dentistry, ${ }^{3}$ Public Health Officer \\ Kantipur Dental College, Kathmandu, Nepal
}

Correspondence: parajeetag@yahoo.com

\section{ABSTRACT}

Objective: To evaluate the anxiety level of parents accompanying their children for the dental treatment.

Materials \& Method: Dental Anxiety Scale-Revised (DAS-R) questionnaire was filled by 101 subjects (53 females and 48 males) visiting the dental department for their children's dental treatment.

Result: $62.4 \%$ parents accompanying their children had no or low anxiety levels and $9.9 \%$ and $5.9 \%$ showed high to severe anxiety levels respectively. There was no statistical significant difference seen between the anxiety levels in male and female parents.

Conclusion: $37.6 \%$ parents accompanying their children to the dentist showed moderate to severe anxiety levels with no significant difference seen in the overall anxiety levels of mothers and fathers.

Key words: dental anxiety, dental anxiety scale, maternal anxiety

\section{INTRODUCTION}

Dental anxiety, a state of unpleasantness with associated fear of danger from within or a learned process of one's own environment is a common hindrance in the dental treatment. The anxiety associated with the dental situation is a concern for the dentist as it leads to avoidance of dental treatment. Approximately 6 to $15 \%$ people worldwide suffer from high dental fear. ' Dental anxiety has multifactorial origin with the major causes being illiteracy, lack of dental awareness, irregular dental attendance, maternal anxiety and socioeconomic status. A traumatic past dental experience and attitude of dentist were found to be fear provoking factors in dental anxiety. ${ }^{2,3}$

The onset of dental anxiety occurs in childhood, peaks in early adulthood and declines with age. ${ }^{2}$ Dental anxiety of childhood and adolescence may persist leading to development of disruptive behavior. ${ }^{4}$
Dental anxiety causes frequent and serious problems for the dentist as well as the patients leading to harmful effects like avoidance and cancellations of dental appointments as well as unacceptable behavior during the procedure like crying, anger. ${ }^{3}$

Anxiety in a child develops with the existence of anxious people around them. Dental behavior of children is under the influence of the parent's attitude and parents with high level of anxiety exert a negative influence on their children. While discussing the role of family's influence on children, Lechner ${ }^{5}$ considered maternal anxiety as the primary factor influencing child behavior. ${ }^{6}$ The literature is replete with articles discussing the influence of maternal anxiety on children but only few studies have been conducted on father's anxiety.

Corah's Dental Anxiety Scale is one of the most widely used and studied instrument for measuring 
Table 1: Distribution of subjects according to age and gender

\begin{tabular}{|l|c|c|c|c|}
\hline Age group & Female & Male & Total & Mean \\
\hline $\mathbf{2 0}-\mathbf{3 1}$ years & 33 & 12 & $45(44.6 \%)$ & \\
\cline { 1 - 4 } $\mathbf{3 2}$-57 years & 25 & 31 & $56(55.4 \%)$ & \multirow{3}{*}{$\mathbf{3 2 . 7 6}$} \\
\hline Total & 58 & 43 & 101 & \\
\hline
\end{tabular}

dental anxiety. Corah's DAS has been modified by the addition of a fifth item that asks about responses to administration of local anesthetic. The modified scale has high levels of reliability and validity. The scale yields a score of 4 to 20 , with scores greater than 15 are indicative of phobic levels of anxiety. ${ }^{1,7-9}$

The purpose of the present study was to evaluate the anxiety level of parents accompanying children for their dental treatment.

\section{MATERIALS AND METHODS}

A cross-sectional study was conducted in Department of Pediatric Dentistry, Kantipur Dental College Teaching Hospital \& Research Center, Kathmandu, Nepal. The time period of the study was from March to May 2013.

Sample selection: A total of 101 subjects including 58 female and 48 male parents accompanying their children to the dentist, willing to participate in the study were selected. Only parents well versed in Nepalese language were included in the study. The samples were asked to complete the questionnaire in the waiting area.

Questionnaire: Questionnaire used was the translated Nepalese version of Dental Anxiety Scale-Revised (DAS-R) which was validated prior to the study. The questionnaire consisted of 5 close ended questions relating to various dental situations and each question had 5 options. After the informed consent was obtained the parents completed the questionnaire in the dental operatory. Confidentiality was maintained. Statistical analysis was carried out using SPSS version 17.

\section{Scoring:}

$a=1, b=2, c=3, d=4, e=5$

Total possible score $=20$

\section{Anxiety rating:}

\begin{tabular}{|l|c|}
\hline Anxiety level & Score \\
\hline No or low anxiety & $<9$ \\
\hline Moderate anxiety & $9-12$ \\
\hline High anxiety & $13-14$ \\
\hline Severe anxiety/phobia & $15-20$ \\
\hline
\end{tabular}

\section{RESULTS}

In the present study anxiety levels of 101 parents accompanying their children aged 20 to 53 years were analyzed. Among the subjects $44.6 \%$ were between 20 to 31 years and $55.4 \%$ were 32 years and more (Table 1).

The present study showed that $62.4 \%$ parents accompanying their children had no or low anxiety level with only $9.9 \%$ and $5.9 \%$ showing high to severe anxiety respectively. $21.8 \%$ parents showed moderate anxiety levels (Figure 1).

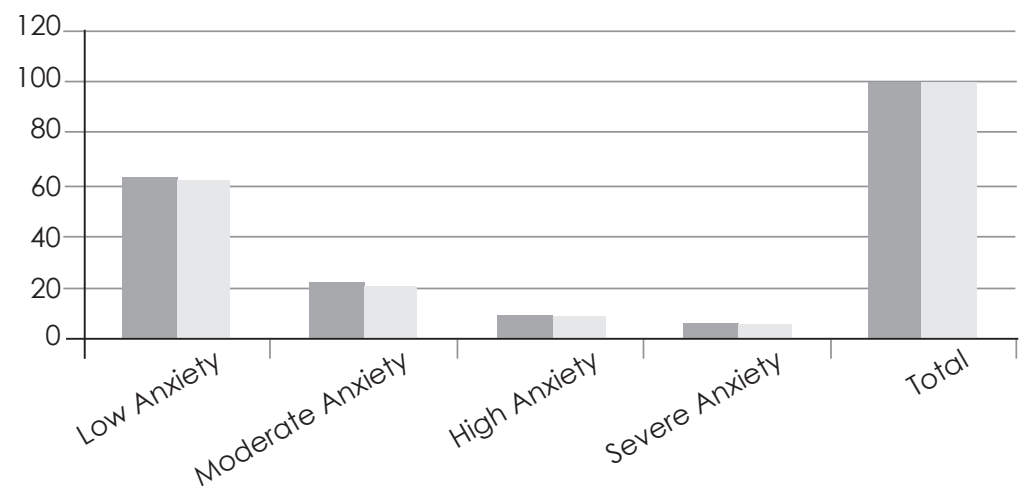

Frequency

Percent

Figure 1: Distribution of anxiety level in total subjects 


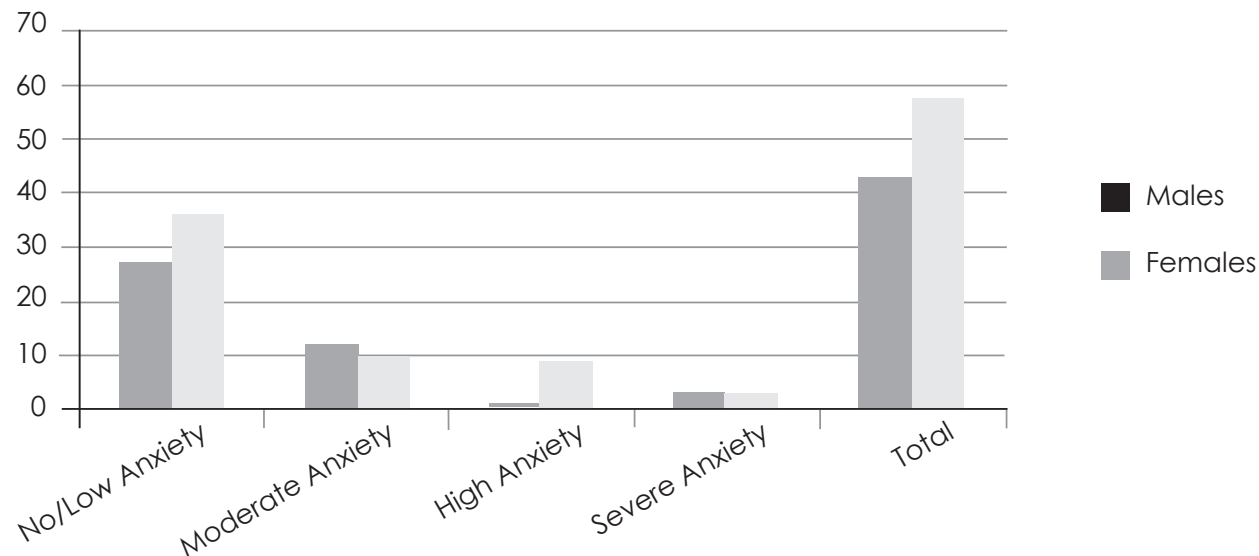

Figure 2: Distribution of anxiety level in male and female subjects

Among the studied sample, $26.7 \%$ males and $35.6 \%$ females showed low anxiety level and equal percentage of males and females showed severe anxiety levels (2.9\%). $8.9 \%$ females showed high anxiety while only $0.9 \%$ males were highly anxious. The finding was not statistically significant ( $p$-value 0.941) (Figure 2).

There was no statistical significant difference between the two age groups of the parental age; $29.7 \%$ of sample less than 32 years and $32.7 \%$ sample more than 32 years showed moderate to severe anxiety ( $p$-value - 0.425) (Table 2).

Table 2: Distribution of anxiety level according to age group

\begin{tabular}{|l|c|c|c|c|}
\hline Age & No / low Anxiety & $\begin{array}{c}\text { Moderate to severe } \\
\text { anxiety }\end{array}$ & Total & p-value \\
\hline$<32$ years & $15(14.8 \%)$ & $30(29.7 \%)$ & $45(44.6 \%)$ & \\
\cline { 1 - 3 } $\mathbf{2 3 2}$ years & $23(22.8 \%)$ & $33(32.7 \%)$ & $56(55.4 \%)$ & \multirow{2}{*}{0.425} \\
\cline { 1 - 4 } Total & $38(37.6 \%)$ & $63(62.4 \%)$ & 101 & \\
\hline
\end{tabular}

The present study based on Dental Anxiety Scale-Revised (DAS-R) questionnaire (Table 3) showed that, $71.3 \%$ of the respondents would look forward to go to the dentist as an enjoyable experience and only $10.9 \%$ would be very frightened of what the dentist does.

According to questionare, $64.4 \%$ of the participants would feel little uneasy waiting for their turn in the chair, $21.8 \%$ would feel relaxed, while the rest would show higher anxiety levels.

While waiting for the dentist to get the drill ready to start working $57.4 \%$ would feel a little uneasy, $16.8 \%$ would feel relaxed, $9.9 \%$ of the participants would be anxious and so anxious that would break out into sweat.

While waiting for the instruments to be ready, $54.5 \%$ would feel a little anxious. $21.8 \%$ would be relaxed while $11.9 \%$ would be anxious. 
Table 3: Distribution of subjects based on the questionnaire

\section{Questions}

Q.1. If you had to go to the dentist tomorrow for a check-up, how would you feel about it?
a. I would look forward to it as a reasonably enjoyable experience.
$72(71.3 \%)$
b. I wouldn't care one way or the other.
$6(5.9 \%)$
c. I would be a little uneasy about it.
$7(6.9 \%)$
d. I would be afraid that it would be unpleasant and painful.
$5(5.0 \%)$
e. I would be very frightened of what the dentist would do.
$11(10.9 \%)$

Q.2. When you are waiting in the dentist's office for your turn in the chair, how do you feel?

\begin{tabular}{|l|r|}
\hline a. Relaxed. & $22(21.8 \%)$ \\
\hline b. A little uneasy. & $65(64.4 \%)$ \\
\hline c. Tense. & $5(5.0 \%)$ \\
\hline d. Anxious. & $7(6.9 \%)$ \\
\hline e. So anxious that I sometimes break out in a sweat or almost feel physically sick. & $2(2.0 \%)$ \\
\hline
\end{tabular}

Q.3. When you are in the dentist's chair waiting while the dentist gets the drill ready to begin working on your teeth, how do you feel?

\begin{tabular}{|l|c}
\hline a. Relaxed. & $17(16.8 \%)$ \\
\hline b. A little uneasy. & $58(57.4 \%)$ \\
\hline c. Tense. & $6(5.9 \%)$ \\
\hline d. Anxious. & $10(9.9 \%)$ \\
\hline e. So anxious that I sometimes break out in a sweat or almost feel physically sick. & $10(9.9 \%)$ \\
\hline
\end{tabular}

Q.4. Imagine you are in the dentist's chair to have your teeth cleaned. While you are waiting and the dentist or hygienist is getting out the instruments which will be used to scrape your teeth around the gums, how do you feel?

\begin{tabular}{|l|c|}
\hline a. Relaxed. & $22(21.8 \%)$ \\
\hline b. A little uneasy. & $55(54.5 \%)$ \\
\hline c. Tense. & $6(5.9 \%)$ \\
\hline d. Anxious. & $12(11.9 \%)$ \\
\hline e. So anxious that I sometimes break out in a sweat or almost feel physically sick. & $6(5.9 \%)$ \\
\hline
\end{tabular}

\section{DISCUSSION}

The present study assessed the dental anxiety level of parents using the validated Nepalese version of Dental Anxiety Scale-Revised (DAS-R). DAS scale is the most widely used measure of dental anxiety and was developed to measure psychological stress. ${ }^{7}$ The Corah Dental Anxiety Scale (DAS) was introduced in 1969 as a brief, valid, and reliable instrument to measure anxiety about dental visits. In 1994, the DAS was revised by Ronis et al $^{10}$ as the Dental Anxiety ScaleRevised (DAS-R) to acknowledge the role of dental hygienists and female dentists in the dental office. 1 The scale consists of four questions related to the dental situations with the first two questions relating to anxiety generally and the latter two relating to anticipated fear of specific stimuli., 7-9

Dental anxiety is seen in approximately (6-15\%) of the population and is a learned process of unpleasantness to one's own environment.1, "1 Similar finding was noted in the present study where $16.8 \%$ of the subjects showed high to severe fear.

Dental anxiety has multifactorial origin, and among the environmental factors parental dental fear is strongly correlated to that of the child. ${ }^{12}$ Markus et $a l^{13}$ in a meta-analysis demonstrated a significant relationship 
between parental and child dental anxiety. Parental anxiety has perhaps received the most attention within the literature as an important external factor that may influence the child's anxiety and behavior within the dental setting. ${ }^{12,14,15}$ In the present study $37.6 \%$ parents accompanying their child for dental treatment showed moderate to severe anxiety levels.

Mothers with high levels of dental anxiety exerting negative influence on their children have been depicted by Lechner ${ }^{5}$ and Ripa. ${ }^{16}$ Folyani et $a l^{17}$ reported significantly high level of dental anxiety among mothers as compared to fathers. Similar finding was reported in a study conducted in Israel by Benjamin and Dan' $^{6}$ that mothers had higher anxiety level as compared to their husbands. Literature is replete with articles suggesting the influence of maternal anxiety in child behavior. $2,5,6,16,17,18$

The influence of dental anxiety of father has been largely ignored. Although many authors have reported that dental anxiety is more common in women than in men. ${ }^{2,17}$ There was no statistically significant difference in the anxiety levels of fathers and mothers in the present study which is in agreement to the findings of Sari et $a^{19}$ and Ersin and Seniz. ${ }^{20}$

Parents' perception of dental appointments being unpleasant may be passed onto children. An assessment of parents fear prior to child's dental treatment may help the clinician in modifying behavior management strategies. Whenever parental anxiety is high, efforts to reduce the parents' level of anxiety may also benefit the child. Providing parents with information about their child's dental treatment has been found to be an effective intervention in reducing the pre-operative anxiety of the parents. ${ }^{14,21}$
Parents are generally seen accompanying their children to the Pediatric dentist and to the Orthodontist. Dental anxiety is therefore not only encountered in parents visiting Pediatric dentist but is common in the Orthodontic clinic as well. Studies have reported high anxiety levels in parents of children awaiting orthodontic treatment which could affect the outcome of their child's treatment. ${ }^{19.20}$

Good dental health education, regular dental visits, good patient-dentist relationship, and effective communication with patients and parents may all contribute to the control of dental anxiety. This study addressed only on parental dental anxiety, the correlation of parent's anxiety and its influence on children remains to be investigated.

\section{CONCLUSION}

It can be concluded from the present study that $37.6 \%$ parents accompanying their children showed moderate to severe anxiety levels. There was no significant difference seen in the anxiety levels between the two age groups. The anxiety levels of mothers and fathers were not significantly different. The dental anxiety levels in parents may influence the anxiety levels of children. Therefore identifying anxiety levels of parents accompanying their children can help the clinician in designing the behavior management strategies for the child accordingly. 


\section{REFERENCES}

1. Hemlatha R. Anxiety assessment in pediatric dental practice. SRM University J Dent Sci 2010;Vol 1(1):75-78.

2. Kulkarni S, Jain M, Mathur A, Mehta P, Gupta R, Goutham B, Prabu D. A relation between dental anxiety, the parental family and regularity of dental attendance in India. J Oral Health Comm Dent 2009; 3(2):29-33.

3. Lara A, Crego A, Romero-Maroto M. Emotional contagion of dental fear to children: the fathers' mediating role in parental transfer of fear. Int J Paed Dent 2012; 22:324-30.

4. Janneke B, Krikken, Arjen J. Van Wijk, Jacob M. Ten Cate \& Jaap S. J. Veerkamp. Measuring dental fear using the CFSS-DS. Do children and parents agree? Int J Paed Dent 2013; 23:94-100.

5. Lechner V. The influence of the family. In: Wright GZ, ed. Behavior Management in Dentistry for children. Philadelphia, PA: W.B. Saunders Co, 1975:73-87.

6. Benjamin Peretz' \& Dan Zadik. Dental anxiety of parents in an Israeli Kibbutz population. Int J Paed Dent 1994;4:87-92.

7. Jason.M. Armfield. How do we measure dental fear and what are we measuring anyway? Oral Health Prev Dent 2010;8:107-15.

8. J. Timothy Newton, Dave J. Buck. Anxiety and Pain Measures in Dentistry: A Guide to Their Quality and Application. JADA 2000;131:1449-57.

9. Patricia A. Doerr, W. Paul Lang, Linda V. Nyquist ,David L. Ronis. Factors associated with dental anxiety. JADA 1998; 129:1111-9.

10. Ronis DL, Hansen CH, Antonakos CL. Equivalance of the original and revised dental anxiety scales. J.Dent Hyg. 1995; 69(6): 270-272.

11. Woosung Sohn, Amid I. Ismail. Regular dental visits and dental anxiety in an adult dentate population. JADA 2005; 136 :58-66.

12. BS Suprabha, Arathi Rao, Shwetha Choudhary, Ramya Shenoy. Child dental fear and behavior: The role of environmental factors in a hospital cohort. J Ind Soc Pedo Prev Dent 201 1; 29(2):95-101.

13. Markus Themessl-Huber, Ruth Freeman, Gerry Humphris, Steve Macgillivray \& Nathalie Terzi. Empirical evidence of the relationship between parental and child dental fear: a structured review and meta-analysis. Int J Paed Dent 2010; 20:83-101

14. Jenny Porritt, Zoe Marshman \& Helen D. Rodd. Understanding children's dental anxiety and psychological approaches to its reduction. Int J Paed Dent 2012; 22:397-405

15. Rasa Raciene. Prevalence of dental fear among Vilnius pupils aged 12 to 15 years. Determining Factors. Stomatologija, Baltic dental and maxillofacial journal 2003; 5:52-56.

16. Ripa LW. Maternal influence on children's behavior in the dental situation. In: Ripa LW, Barenie JT, eds. Management of Dental Behavior in Children. Littleton, MA: PSG Publishing, 1979; 15-76.

17. M.O.Folayan, C.A. Adekoya-Sofowora,O.D.Otuyemi1 \& D.Ufomata. Parental anxiety as a possible predisposing factor to child dental anxiety in patients seen in a suburban dental hospital in Nigeria. Int J Paed Dent 2002; 12:255-59.

18. Chen-Yi Lee,Yong-Yuan Chang,\& Shun-Te Huang. The clinically related predictors of dental fear in Taiwanese children. Int J Paed Dent 2008; 18:415-422.

19. Zafer Sari,Tancan Uysal, Ali Ihya Karaman,Nurten Sargin,Omer Ure. Does orthodontic treatment affect patients' and parents' anxiety levels? European Journal of Orthodontics 2005; 27:155-159.

20. Ersin Ylldirım, Seniz Karacay. Evaluation of anxiety level changes during the first three months of orthodontic treatment. http:// dx.doi.org/10.4041/kjod.2012.42.4.201.

21. Klingberg G, Berggren U, Carlsson SG, Noren JG.Child dental fear cause-related factors and clinical effects. Eur J Oral Sci 1995; 103: 405-412. 